\title{
Akran Arabuluculuğu Programının Ergenlerin Sosyal Becerilerine Etkisinin Incelenmesi
}

\author{
Muhammed YILDIZ
}

Öz

Araştırma akran arabuluculuğunun lise öğrencilerinin sosyal beceri düzeylerine etkisini incelemek amacıyla lisede öğrenim gören 72 öğrenciyle yapılmıştır. Öğrencilere Sosyal Beceri Envanteri uygulanmıştır. Gönüllü olan 35 öğrenci daha önce yetiştirilen akran arabulucu öğrencilerin düzenlediği çatışma çözme programlarına katılmışlardır. Programların sonunda deney grubundaki 35 öğrenci ve kontrol grubundaki 37 öğrenciye tekrar Sosyal Beceri Envanteri uygulanmıştır. Araştırmanın sonuçları akran arabuluculuğu programına katılan öğrencilerin sosyal beceri seviyelerinin anlamlı bir biçimde arttığını ortaya koymaktadır.

Anahtar Kelimeler: Akran Arabuluculuğu, Ergenler, Sosyal Beceri

Investigating the Impact of Peer Mediation Program on Social Skills of the Adolescents

\begin{abstract}
The study was conducted with 72 students studying in high school to investigate the effect of peer mediation on the level of social skills of high school students. Social Skills Inventory was applied to students. 35 volunteers participated in conflict resolution programs organized by peer mediation students who were raised before. At the end of the programs, 35 students in the experimental group and 37 students in the control group were applied again to the Social Skill Inventory. The results of the study show that the social skills levels of the students participating in the peer mediation program increased significantly.
\end{abstract}

Key Words: Peer Mediation, Adolescents, Social Skills

\footnotetext{
${ }^{1}$ Uzm. Psk. Dan, İstanbul Üniversitesi, Eğitim Bilimleri Enstitüsü, Rehberlik ve Psikolojik Danışmanlık Anabilim Dalı, Doktora Öğrencisi, İstanbul/ Türkiye, muhammed.yildiz@ogr.iu.edu.tr
} 


\section{Giriş}

Okullarda eğitim öğretim faaliyetlerini aksatan, okulun atmosferini zedeleyen davranışların başında şiddet gelmektedir. Öğrenciler okul içinde ve okul dışında birbirlerine şiddet uygulayabilmekte, bu da bireylerin okulda kendilerini güven içinde, neşeli ve huzurlu hissetmelerine engel olabilmektedir. Bu durum sadece öğrencilerin değil aynı zamanda öğretmenlerin de okula karşı olumlu tutum sergilemelerine engel olabilmekte, aynı zamanda uzun vadede okuldaki bireylerin akademik başarılarını düşürebilmektedir (Türk ve Türnüklü, 2013). Çok fazla şiddet ve kavganın olduğu okulların bütün enerjileri öğrenci disiplin problemlerine gitmekte okulun olumlu atmosferi zedelenmekte ve akademik etkinliklere yeteri kadar zaman ayrılmamaktadır. Okullarda öğrencilerin diğerleriyle aralarında gerçekleșen problemlerin ve anlaşmazlıkların demokratik ve işlevsel bir biçimde çözülebilmesi için bireylere anlaşmazlıkların çözümü, ortak noktalarda anlaşabilme ve akran arabuluculuğu becerilerinin kazandırıması gerekmektedir. Çatışma çözümü için verilen eğitimlerde bireyler çatışmalarına işlevsel çözümler getirebilmek için müzakere yapmayı öğrenirler (Kaçmaz, Türnüklü ve Türk, 2011). Dolayısıyla sorunlar işlevsel ve sağlıklı bir biçimde dile getirilip çözüme kavuştuğu için saldırgan davranışlar önlenmiş olmaktadır.

Müzakere, hem kişilerin mutabık kaldıkları hem de anlaşamadıkları noktalarda anlaşmak isteyen kişilerin bir ortak çözüm üzerinde beraberce çalıştıkları bir faaliyettir (Stevahn ve Johnson, 1997). Dolayısıyla müzakere olumlu bir süreçtir ve sorunların saldırgan bir biçimde çözülmeye çalışılmasının önüne geçmektedir. Günümüzde ergenler arasında saldırgan davranışların artması, okullarda meydana gelen şiddetin nedenlerinin incelenmesini ve yaşanan bu olayların ortadan kalkması için yapılacakların araştırılmasının zorunluluğunu ortaya koymuştur. Araştırmalar müzakerenin olmadığı okullarda herhangi bir problem durumunda bireylerin öfkelerini kontrol edemediklerini, arkadaşlarına sözel ya da fiziksel anlamda saldırı gerçekleştirdiklerini ortaya koymaktadır (Gentry, 2000). Akran arabuluculuk, arabulucu olarak tanımlanan tarafsız konumda bulunan bir bireyin, kişilerin problemlerini, çatışmalarını müzakere etmede kendilerine yardım ettiği bir süreçtir. Tüm bu süreçler başından sonuna kadar yapılandırılmıştır (Johnson ve Johnson, 1995). Akran arabulucu, anlaşmazlığa düşen ve çatışma yasayan bireylerin ötekini anlaması 
için bir diğerini dinlemesine ve anlamasına katkıda bulunur (Johnson ve Johnson, 1995). Böylece bencilce ve anlaşılmaz tutumlar yerini empatik ve diğerini saygın gören bir bakış açısına bırakır. Akran arabuluculuk süreci, anlaşmazlığa düşen tarafların kendilerine olan güveninin artmasına yol açar. Bireylerin sorunları anlama ve çatışma çözme kabiliyetlerinin gelişmesine de destek olur (Haynes, 1993). Bireylerin karşılanmayan psikolojik ihtiyaçları, sınırlı kaynaklar, birbirlerinden farklı inanç ve değer sistemlerine sahip olmaları nedeniyle çatışmalar yaşanabilir (Taştan, 2004). Ancak bu farklılıklar bireylerin birbirlerine düşmanca ve anlaşmaz tutumlar yoluyla karşı koymalarını gerektirmez. Akran arabulucu, bireylerin sahip olduğu farklılıkları birbirlerine gösterir ve ortak noktalar bulmaları ve birbirlerinin haklarına saygı göstermeleri için bilgi ve becerilerini kullanır. Kişiler, fikirlerinin birbirine uymaması, ortak bir kavram konusunda uzlaşamamaları, herhangi bir konuda çıkar çatışması yaşamaları, farklı gelişim özelliklerine sahip olmaları nedeniyle çatışma yaşayabilirler (Taştan, 2004). Burada tüm çatışma türlerinde dikkat çeken ortak özellik ötekinin fikirlerine yabancı olma ve onun varoluşunu hissedememe olarak ifade edilebilir. Bireyler çatışma durumunda bir takım eylemlerde bulunabilirler. $\mathrm{Bu}$ eylemlerden ilki zorlamadır. Bireyler kendi istek ve beklentilerini zorla diğerine kabul ettirme yoluna gidebilirler. Böyle bir tutum sağlıksız olmasının yanı sıra, şiddetle sonuçlanması muhtemel bir davranıştır. Özellikle fiziksel olarak diğerinden daha güçlü bir birey kaba kuvvet kullanarak diğerinin hakkını çiğneyebilir. Öğrencilerin büyük bir kısmında görülen zorbalık davranışının nedeni, kendi istek ve amaçlarını diğerine kaba kuvvet ve güç göstererek kabul ettirme düşüncesidir (Womack, 1990) ve (Boardman ve Horowitz, 1994). Bir diğer davranış biçimi uyma davranışıdır. Bu davranış biçiminde taraflardan biri kendi hakkından vazgeçerek karşısındakinin isteklerini yerine getirir. Hiç kuşkusuz böyle bir tutumun da sağlıklı olmadığı ifade edilebilir. Çünkü istenen sağlıklı tutum her iki tarafında duygularını ve isteklerini demokratik bir biçimde ifade etmesini sağlamaktır (Womack, 1990) ve (Boardman ve Horowitz, 1994). Diğer bir davranış ise kaçınma davranışıdır. Bu davranış biçiminde her iki taraf da herhangi bir olumlu tutum içine girmekten kaçınır, taraflar kendini iletişime kapatır ve sorun ile ilgili konuşulmaz. Sorun çözülmediği gibi aynı zamanda yeni ve daha büyük sorunların gelişimi için bir potansiyel olmaktadır (Womack, 1990) ve (Boardman ve Horowitz, 1994). Diğer bir biçimse uzlaşmadır, her iki 
tarafta kendi haklarının bir bölümünden vazgeçerek orta bir yol bulurlar. Taraflar kendi ısrarla üzerinde durdukları haklarından vazgeçebilirler (Womack, 1990) ve (Boardman ve Horowitz, 1994). En son davranış biçimiyse en sağlıklı yaklaşım olan işbirliği yöntemidir. Bu davranış biçiminde her iki taraf da sorunun çözümü için demokratik haklarından vazgeçmez, sorundan kaçmazlar ve ortak makul noktalarda birleșirler (Womack, 1990) ve (Boardman ve Horowitz, 1994). Ancak bu her zaman kolay olmayabilir. Kaçmaz ve Türnüklü’nün (2011) yaptığı çalışmada, çatışma yaşayan bireylerin kendilerini ifade etmeleri esnasında duygusal direnç sergiledikleri ortaya konmuştur.

Akran arabuluculuğunun bireylere birçok yararı bulunmaktadır. Öğrencilerin daha barışçıl yöntemler öğrenmeleri, öğrencilerin saldırgan ve barışçıl olmayan yöntemler yerine karşıdakine saygı, iletişim ve empati kurma gibi temel insani becerileri öğrenmeleri, çatışmaların bir sorun değil de ileride karşılaşacakları problemlerin çözümü için bir prova niteliği taşıdığı ve kendilerini hayata hazırlayan bir süreç gibi algılanması, bu eğitimler marifetiyle bireylerin kendilerine güvenlerini artıracak daha fazla saygı daha fazla özgüven yaşayacakları ve sorunlarının çözümü için daha fazla inisiyatif alacakları yaşantılar sağlaması gibi faydalar sayılabilir (Türnüklü, Kaçmaz, Gürler, Yaka, Türk, Kalender, Zengin, 2009). Öğrenciler sorunların çözümü için birçok beceriyi edinecek, böylece liderlik özellikleri gelișecektir. Öğrenciler sorunlarını etkin bir biçimde çözdükleri takdirde kalan zamanlarını akademik faaliyetleri için kullanabileceklerdir. Öğrenciler birçok problemin ve anlaşmazlığın çözümünü henüz çocukluk yıllarında kazandıkları için, ilerleyen yaşamlarında daha olgun bireyler halini alabileceklerdir (Türnüklü vd, 2009). Çatışmalarının çözümünde başarılı olmaları ruh sağlıklarını olumlu bir biçiminde etkileyecektir. Sorunlar büyümeden önlendiği için saldırganlık ve şiddet gibi istenmeyen davranışlar daha oluşmadan engellenmiş olacaktır. Aynı zamanda okulda şiddet ve saldırganlıkla ilgili yapılacak programların yerini akademik çalışmalar alacağı için ekonomik açıdan da gayet makul sonuçlar vermektedir (Türnüklü vd, 2009).

Konuyla ilgili çalışmalara bakıldığında, akran arabuluculuğunun etkililiğiyle ilgili olarak Johnson ve arkadaşlarının (1996) 323 öğrenciyle yaptığı araştırmasında, öğrenciler yaşadıkları çatışmaları akran arabuluculuk yöntemiyle çözmüştür. Lupton-Smith ve Carruthers (1996) okullarda akran 
arabuluculuğu çalışmalarının etkililiğini araştırmış ve bu programların çatışmaların çözümünde etkin olduğunu ortaya koymuştur. Türnüklü ve arkadaşları (2009) araştırmasında çatışma çözme ve akran arabuluculuğu çalışmalarının etkililiğini değerlendirmişler ve öğrencilerin akranlarıyla yaşadıkları çatışmaları bu yöntemlerle çözdüklerini ve \%98 oranında çatışmaların anlaşmayla sonuçlandığını ortaya koymuşlardır. Özgit (1991)'in çalışmasında üniversite öğrencilerinde çatışma çözme becerilerini kazanan grupla, kontrol grubundaki bireyler karşılaştırılmış ve program uygulanan üniversite öğrencilerinin çatışma eğilimlerinin, diğer gruba oranla anlamlı bir biçimde azaldığını ortaya koymuştur. Kavalcı (2001), araştırmasında, çatışma çözme eğitimi alan öğrencilerin yaşadıkları çatışmaları daha etkin bir biçimde çözdükleri ve bu becerilerin çatışma çözümü üzerinde olumlu bir etkiye sahip olduğu ortaya çıkmıştır.

Koruklu'nun (2008) araştırmasında okulda arabuluculuk modeli uygulandıktan sonra öğrencilerin öğretmenlere daha az şikâyet yansıttığı ve öğrencilerin, bir problem ortaya çıktığı zaman öğretmene değil akran arabulucuya danıştıkları ortaya çıkmıştır. Bunun doğal bir sonucu olarak da okulda bulunan idareci ve öğretmenler disiplin problemleriyle daha az uğraşacaklardır. Arabuluculuk eğitimi, her eğitim kademesinde bulunan bireylerde olumlu sonuçlar vermektedir. Koruklu ve Yılmaz'ın (2010) araştırması, çatışma çözme ve arabuluculuk eğitiminin, altı yaş grubu bireylerin problem çözme becerilerinde olumlu bir etkisinin olduğunu göstermektedir. Etkililiğiyle ilgili birçok yayın bulunmasına rağmen maalesef akran arabuluculuğunun okul rehberlik servislerinde yeterince kullanıldığını söylemek oldukça güçtür. Uzbaş'ın (2010) yaptığı araştırmada okul psikolojik danışmanlarının akran arabuluculuğuyla ilgili yaptıkları çalışmaların toplam çalışmalar arasındaki oranının \%2.5 olduğu ortaya çıkmıştır.

Sosyal beceri kavramı, bireyin sosyal çevresine uyum sağlaması, sağlıklı iletişim biçimleri edinerek, ileride ortaya çıkabilecek problemlerle baş etme becerileri olarak ifade edilebilir (Matson, Matson ve Rivet, 2007). Birey için diğerlerinin olumlu geribildirimler vermesine neden olabilecek ve olumsuz tepkileri engelleyebilecek bir takım beceriler edinmek önemlidir. İnsanlar, diğerleriyle etkileşimi olanaklı hale getirecek ve sosyal açıdan onaylanabilir olan davranışları edinmek ister. Bu davranış biçimleri sosyal 
beceri olarak ifade edilebilir (Yüksel, 1998). Bir diğer tanımda sosyal beceriler diğerleriyle toplumsal açıdan onaylanabilir, kişi açısından yararlı ve bununla beraber başkalarına da faydalı olan sosyal açıdan diğerleriyle etkileşim kurma yeteneği olarak ifade edilebilir (Combs ve Slaby, 1977). Sosyal beceri kavramı insanların toplumca kendine biçilen rolleri gerçekleştirdiğini ortaya koymak için lazım olan birtakım davranış biçimleridir (McFall, 1982).

\section{Araştırmanın soruları}

Araştırmada aşağıdaki probleme yanıt aranmıștır.

\section{Yaşadıkları çatışmaları, akran arabulucu öğrencilerle işbirliği içinde çözmeye çalışan ergenlerde, yapılan çalışmalar, sosyal becerilerine etki etmekte midir?}

\section{Yöntem}

Araştırma deneysel bir çalışmadır. Deney grubu, yaşadıkları çatışmaları, araştırmacı tarafından eğitilen akran arabulucu öğrencilerle işbirliği içinde çözmeye çalışmışlardır. Kontrol grubuna ise herhangi bir işlem yapılmamıştır. Çalışmada ön test son test kontrol gruplu deneysel desen kullanılmıştır.

\section{ișlem}

Araştırma tamamı aynı okulda öğrenim gören 72 lise öğrencisiyle yapılmıştır. Öğrencilerin 32’si kız (\%44.4), 40’ı erkektir (\%55.6). Öğrencilerin 14'ü 15 yaşında (\%19.4), 18'i 16 yaşında (\%25), 10'u 17 yaşında (\%13.9), 16'sı 18 yaşında (\%22.2), 14’ü 19 yaşında (\%19.4), 24’ü 9.sınıf (\%33.3), 24’ü 10.sınıf (\%33.3), 10’u 11.sınıf (\%13.9), 14’ü 12.sınıf (\%19.4) öğrencisidir. Çalışmadan önce tüm öğrencilere Sosyal Beceri Envanteri uygulanmıştır. Deney ve kontrol grupları oluşturulurken Sosyal Beceri Envanteri Ölçeği puanlarına göre aritmetik ortalamaları ve standart sapmaları birbirine yakın iki grup oluşturulmuştur. Böylece öğrencilerin 35 ’ deney grubu, 37'si kontrol grubuna atanmıştır. Araștırmacı tarafından daha önce altı hafta ve her bir oturumu $60 \mathrm{dk}$. süren eğitimlerle akran arabulucu öğrenciler yetiştirilmiştir. $\mathrm{Bu}$ oturumlarda akran arabulucu öğrencilere çatışma çözmede görüşme yapma, çatışma nedenleri, iletişim becerileri ve empati eğitimleri verilmiştir. Eğitimlerin bitiminde, akran arabulucu öğrenciler, deney grubundaki öğrencilere, bir eğitim öğretim dönemi boyunca okulda, akran arabuluculuğuna ihtiyaç duyulan 
olaylarda, programda edindikleri becerileri uygulamışlardır. Dolayısıyla deney grubuna dâhil edilen 35 öğrenci, bir eğitim öğretim dönemi boyunca yaşadıkları çatışmaları akran arabulucularla çözmeye çalışmışlardır. Çalışmaların bitiminde deney ve kontrol grubundaki öğrencilere Sosyal Beceri Envanteri tekrar uygulanmıştır.

\section{Veri Toplama Araçları}

Sosyal Beceri Envanteri: Bireylerde sosyal becerileri ölçmek için 1986 yılında Riggio tarafından geliştirilmiştir. Sosyal Beceri Envanterinde 6 alt ölçek ve toplam 90 madde bulunmaktadır (Gülay, 2008). Ölçeğin ülkemize uyarlanması, Yüksel (1998) tarafından gerçekleştirilmiştir. Cevaplama sistemi olarak beşli likert tipi bir ölçek olan Sosyal Beceri Envanterinden alınabilecek olan en düşük puan 90, ölçekten alınabilecek en yüksek puansa 450'dir (Yüksel, 2004). Ölçeğin uyarlama çalışmaları üniversite öğrencileriyle yapılmıştır. Ölçeğin güvenirlik çalışmaları kapsamında yapılan test tekrar testi sonucunda ölçeğin tamamına ilişkin güvenirlik katsayısı 0.92 bulunmuştur. Ölçeğin tamamına ilişkin cronbach alpha güvenirlik katsayısı 0.85 bulunmuştur. Geçerlik çalışmaları kapsamında benzer ölçekler geçerliği çalışması yapılmış ve $r=0.63$ bulunmuştur (Yüksel, 1997).

\section{Bulgular}

Veri setinin normal dağılım gösterip göstermediğini tespit etmek amacıyla Kolmogrov Smirnov testi yapılmıştır. Testin sonucunda anlamlılık değeri $\mathrm{p}<0.05$ çıkması üzerine non-parametric istatistiksel yöntemlerden Mann-Whitney $U$ Testi ve Wilcoxon Eşleştirilmiş íki Örneklem Testi kullanılmıştır. Çalışmada anlamlılık değeri olarak $p<0.05$ alınmıştır. Tablo 1'de deney ve kontrol gruplarının ön test ve son test puanlarının değerleri verilmiştir. Burada önemli olan nokta, deney ve kontrol gruplarının aritmetik ortalama ve standart sapma değerleri açısından birbirine yakın olmalarıdır. Grupların son test ortalamalarının sağlıklı bir biçimde değerlendirilmesi için iki grubunda deney öncesi neredeyse aynı gruplar olması şartı aranmıştır. 
Tablo 1. Deney ve Kontrol Gruplarının Ön test ve Son Testten Aldıkları Puanların Ortalama ve Standart Sapma Değerleri

\begin{tabular}{ccccccc}
\hline & \multicolumn{3}{c}{ Deney } & & \multicolumn{3}{c}{ Kontrol } \\
& $N$ & $\bar{X}$ & Ss & $N$ & $\bar{X}$ & Ss \\
\hline Ön test & 35 & 305.48 & 79.89 & 37 & 308.81 & 73.81 \\
Son test & 35 & 341.62 & 72.47 & 37 & 306.40 & 67.72 \\
\hline
\end{tabular}

Tablo 1 incelendiğinde deney grubunun ön test ortalaması 305.48, standart sapması 79.89; kontrol grubunun ön test ortalaması 308.81, standart sapması 73.81'dir. Akran arabuluculuğu çalışmalarından faydalanan deney grubunun son test ortalaması 341.62, standart sapması 72.47 olmuştur. Herhangi bir işlem yapılmayan kontrol grubunun son test ortalaması 306.40, standart sapması 67.72 olmuştur. 
Tablo 2. Deney ve Kontrol Grubu Ön Test Sonuçları için Yapılan Mann-Whitney U Testi Sonuçları

\begin{tabular}{|c|c|c|c|c|c|c|c|}
\hline & Grup & $\bar{X}$ & Sıra Ortalaması & Sıralar Toplamı & $U$ & $Z$ & $p$ \\
\hline \multirow{3}{*}{ Ön Test } & Deney & 35 & 35.86 & 1255 & \multirow{3}{*}{625} & \multirow{3}{*}{-0.254} & \multirow{3}{*}{0.800} \\
\hline & & & & & & & \\
\hline & Kontrol & 37 & 37.11 & 1373 & & & \\
\hline
\end{tabular}

Tablo 2 incelendiğinde deney grubundaki öğrencilerle (Sıra Ort.=35.86), kontrol grubundaki öğrenciler arasında (Sıra Ort.=37.11) anlamlı bir fark ortaya çıkmamıştır. $(U=625, p=0.800>0.05)$. Bu durum deney ve kontrol gruplarının ön test skorlarına göre benzer gruplar olduğunu ortaya koymaktadır.

Tablo 3. Deney ve Kontrol Grubu Son Test Sonuçları için Yapılan Mann-Whitney U Testi Sonuçları

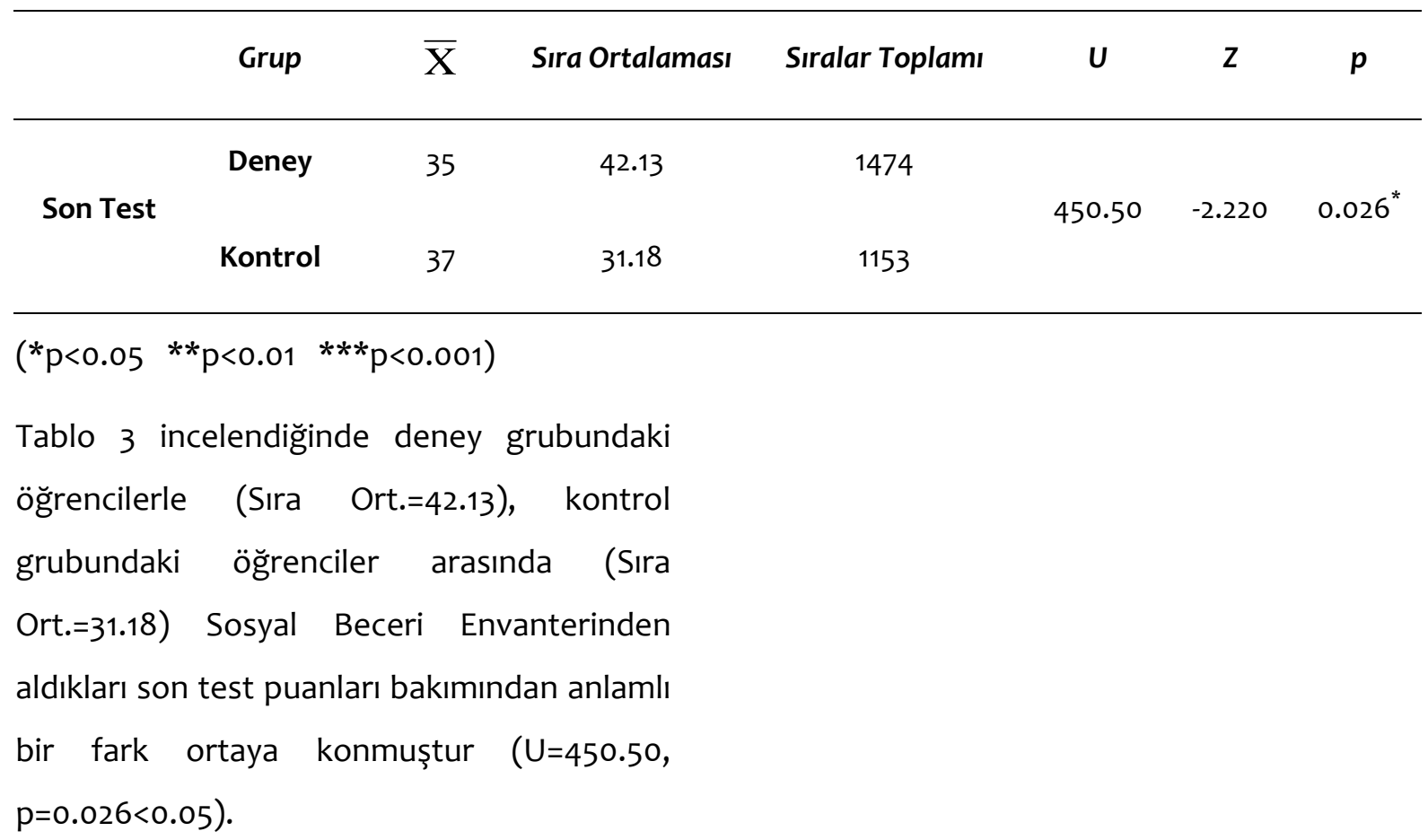


Tablo 4. Deney Grubu Ön Test ve Son Test Sonuçları için Yapılan Wilcoxon Eşleştirilmiş iki Örneklem Testi Sonuçları

\begin{tabular}{ccccccc}
\hline Sosyal & \multicolumn{1}{c}{$\boldsymbol{N}$} & Sira Ortalaması & Sira Toplamı & Z & $p$ \\
\cline { 2 - 6 } Beceri & Negatif SIra & 11 & 11.05 & 121.50 & & \\
Envanteri & Pozitif SIra & 24 & 21.19 & 508.50 & -3.170 & $0.002^{* *}$ \\
Ön test- & Esit & 0 & & & & \\
Son test & Toplam & 35 & & & \\
\hline
\end{tabular}

$\left({ }^{*} \mathrm{p}<0.05 * * \mathrm{p}<0.01 * * * \mathrm{p}<0.001\right)$

Tablo 4 incelendiğinde deney grubundaki öğrencilerin ön test ve son test puanları anlamlı bir biçimde farklıdır (Z:-3.170, $\mathrm{p}=0.002<0.05)$. Dolayısıyla yaşadıkları çatışmaları akran arabulucu öğrencilerin yardımıyla çözmeye çalışan öğrencilerin sosyal beceri düzeyleri anlamlı bir biçimde artmıştır.

\section{Tartışma}

Araştırmanın sonuçları, çatışma durumlarında akran arabulucu öğrencilerden destek alan ergenlerin sosyal beceri düzeylerinin arttığını ortaya koymaktadır. Johnson ve arkadaşlarının (1996), Lupton-Smith ve Carruthers (1996)'ın, Türnüklü ve arkadaşlarının (2009), Özgit (1991)'in, Kavalcı (2001)'nın ve Koruklu ve Yilmaz'ın (2010) yaptığı çalışmalarda akran arabuluculuğunun çatışma çözmede etkili bir yol olduğu ortaya konarken, bu çalışmada, akran arabuluculuğunun bireylerin sosyal becerilerinin gelişmesine katkıda bulunduğu ortaya konmuştur. İlgili literatür incelendiğinde akran arabuluculuğuyla ilgili olarak yapılan çalışmalarda daha çok akran arabuluculuğunun çatışma çözme üzerindeki etkisi incelenmiş olup bu çalışmada ise akran arabuluculuğunun sosyal beceri üzerindeki etkisi incelenmiştir. Yaşadıkları çatışmaları akran arabulucu öğrencilerin yardımıyla çözmeye çalışan bireyler akran ilişkilerinde ortaya çıkan çatışma durumlarında uygun çatışma çözme yöntemlerini kullanarak sosyal beceri düzeylerini artırmışlardır. Akran arabuluculuğu çalışmaları birçok açıdan faydalı olabilir. Akran arabulucu öğrencilerin yetiştirilmesi psikolojik danışmanların üzerindeki iş yükünü azaltabilir. Birçok 
problemin çözümünde etkili bir yol olarak kullanılabilir. Erken müdahale, önleme çalışmaları kapsamında faydalı sonuçlar verebilir. Üstelik okul psikolojik danışmanına gitmeye çekinen ya da bu tür problemlerin çözümü için, yardım almayı düşünmeyen bireyler için, bu tür çalıșmalar etkili bir yol olabilir. Ayrıca akran arabuluculuğu etkinlikleriyle okul psikolojik danışma ve rehberlik çalışmalarında yer alan iletişim, öfke kontrolü, çatışma çözme, sosyal beceri eğitimi gibi birçok faaliyet daha hızlı, daha ulaşılabilir bir şekilde gerçekleştirilebilir. Bunların yanı sıra ergenlik dönemindeki bireyler sorunlarının çözümü için akranlarıyla daha rahat iletişim kurabilirler. Ergenlik döneminde bulunan ve arkadaş ilişkilerine çok önem veren lise öğrencilerinin yaşadıkları problemlerin çözümünde, akran arabuluculuğu çalışmaları daha etkili olabilir. Avrupa ve Amerika eğitim sisteminde çok yaygın olarak kullanılan akran arabuluculuğu ile ilgili olarak ülkemizde bu tür çalışmaların yaygınlığının artırılması gerekmektedir. Her eğitim kademesinde akran arabulucular yetiştirilerek öğrencilerin bu tür çalışmalara daha kolay ulaşması sağlanmalıdır. Akran arabuluculuğu etkinliklerin sayısının artırılması, okuldaki tüm öğrenciler olmasa da belirli sayıda öğrenci yetiștirilerek bu faaliyetlerin kapsamının artırılması gerekmektedir.

\section{Kaynakça}

Boardman, S. K. \& Horowitz, S. V. (1994). Constructive conflict management and social problems: An introduction. Journal of Social Issues, 50(1), 1-12.

Combs, M.L., \& Slaby, D.A. (1977). Social skills training with children advances in clinical child psychology. New York: Plenum 1, 161201.

Gentry, W. D. (2000). Anger free. Ten basic steps to managing your anger. New York: Harper Collins Publishers Inc.

Gülay, O. (2008). Ortaögretim 9. sınıf beden egitimi dersinde isbirlikli oyunların ögrencilerin sosyal beceri düzeylerine ve beden egitimi dersine yönelik tutumlarına etkisi. Yayınlanmamış Yüksek Lisans Tezi, Bolu: Bolu Abant Izzet Baysal Üniversitesi Sosyal Bilimler Enstitüsü. 
Haynes, J. (1993). Alternative dispute resolution. The fundementals of family mediation. London: Old Bailey Press.

Johnson, W.D., Johnson, T.R. (1995). Teaching students to be peacemakers. Edina, MN: Interaction Book Co.

Johnson, D. W., Johnson, R. T., Mithcell, J., Cotten, B., Harris,D., \& Louison, S. (1996). Effectiveness of conflict managers in an inner-city elementary school. Journal of Educational Research. 89(5), 280-286.

Kaçmaz, T., ve Türnüklü, A. (2011). Akran arabulucuların perspektifinden çatışan öğrencilerin arabuluculuk sürecinde yaşadığı zorluklar. Ilköğretim Online, 10(3).

Kaçmaz, T., Türnüklü, A., ve Türk, F. (2011). Akran arabulucuların gözünden ilköğretim öğrencilerinin arabuluculuk sürecinde yaşadıkları güçlüklerin incelenmesi. Kuram ve Uygulamada Eğitim Yönetimi, 17(4), 555-579.
Kavalcı, Z. (2001). Çatışma çözme eğitimi programının üniversite öğrencilerinin çatışma çözme biçimleri üzerindeki etkisi. Yayınlanmamış Yüksek Lisans Tezi, Ankara: Hacettepe Üniversitesi Sosyal Bilimler Enstitüsü.

Koruklu, N. (2008). Okullarda yaşanan şiddet olaylarını azaltmaya yönelik tüm okulu kapsayan arabuluculuk modelinin uygulanmasına ilişkin bir çalıșma. Communication in Peace/Conflict in Communication. 171.

Koruklu, N., ve Yılmaz, N. (2010). Çatışma çözme ve arabuluculuk eğitimi programının okulöncesi kurumlara devam eden çocukların problem çözme becerisine etkisi. Adnan Menderes Üniversitesi Eğitim Fakültesi Eğitim Bilimleri Dergisi. 1(1).

Lupton-Smith, H.S.,\& Carruthers, W.L. (1996). Conflict resolution as peer mediation programs: experiences in three middle schools. Intervention in School and Clinic, 36(2), 94-100. 
Matson, J.L., Matson, M.L., \& Rivet, T.T. (2007). Social skills treatments with children with autism spectrum disorders. Behavior Modification, 31, 682-707.

McFall, R.M. (1982). A review and Türk, F., ve Türnüklü, A. (2013). Akran arabuluculuk eğitiminin lise öğrencilerinin çatışmaları üzerindeki etkisinin incelenmesi. Sosyal Bilimler Dergisi, 3(5), $55-68$

reformulation of the concept of social skills. Behavioral Assessment, 4, 1-33.

Türnüklü, A., Kaçmaz, T., Gürler, S., Yaka, A., Türk, U.F., Kalender, U.A., ve Zengin, U.F. Anlaşmazlık çözümü, müzakere ve akran arabuluculuk. TÜBITAK. verilen eğitimin iletişim çatışmalarına girme eğilimi üzerindeki etkisi. Yayınlanmamış Yüksek Lisans Tezi, İstanbul: Marmara Üniversitesi Sosyal Bilimler Enstitüsü.

Stevahn, L., \& Johnson, D. W. (1997). Effects Türnüklü, A., Kaçmaz, T., İkiz, E., ve Balcı, F. (2009). Liselerde öğrenci şiddetinin önlenmesi anlaşmazlık çözümü, müzakere ve akran-arabuluculuk eğitim programı. Maya Akademi. Ankara.

on high school students of conflict resolution training integrated into English literature. Journal of Social Psychology, 137(3), 302-315.

Taştan, N.(2004). Çatışma çözme ve akran arabuluculuğu eğitimi programlarının Uzbaş, A. (2010). Okul psikolojik danışmanlarının okulda saldırganlık ve şiddete yönelik görüşlerinin değerlendirilmesi. Mehmet Akif Ersoy Üniversitesi Eğitim Fakültesi Dergisi, (18), 90-110. ilköğretim altıncı sınıf öğrencilerinin çatışma çözme ve akran arabuluculuğu becerilerine etkisi. Yayınlanmamış Doktora Tezi, Ankara: Ankara Üniversitesi Eğitim Bilimleri Enstitüsü. 
Womack, D.F. (1990). Theory and research in conflict management. In M. A. Rahim (Ed.), applied communications research in negotiation: Implications for practitioners (p. 32-53). New York: Library of Congress, Publication Data.

Yüksel, G. (1997). Sosyal beceri eğitiminin üniversite öğrencilerinin sosyal beceri düzeyine etkisi. Yayınlanmamış Doktora Tezi, Ankara: Gazi Üniversitesi Eğitim Bilimleri Enstitüsü.
Yüksel, G. (1998). Sosyal beceri envanterinin Türkçe'ye uyarlanması geçerlik ve güvenirlik çalışmaları. Psikolojik Danışma ve Rehberlik Dergisi, 2(9), 39-48.

Yüksel, G. (1998). Ögretmen adayı ögrencilerin sosyal beceri düzeylerinin bazı değişkenler açısından yordanması. Gazi Egitim Fakültesi Dergisi, 19(2), 97-109.

Yüksel, G. (2004). Sosyal beceri envanteri el kitabı. Ankara: Asıl Yayınevi. 